\title{
A Comparative study of controllers for stabilizing a Rotary Inverted Pendulum
}

\author{
Velchuri Sirisha and Dr. Anjali. S. Junghare \\ Electrical Engineering Department, Visvesvaraya National Institute of Technology, \\ Nagpur, India
}

\begin{abstract}
This paper describes comparative study of various controllers on Rotary Inverted Pendulum (RIP). PID, LQR, FUZZY LOGIC and Hœ controllers are tried on RIP in MatLab Simulink. The same four controllers have been tested on test bed of RIP system the controllers are compared from various aspects. The controllers in simulink are compared with the controllers in real time.
\end{abstract}

\section{Keywords}

Fuzzy Logic, Hळ, LQR, PID, RIP

\section{Introduction}

A typical unstable non-linear Inverted Pendulum system is often used as a benchmark to study various control techniques in control engineering. Analysis of controllers on RIP illustrates the analysis in cases such as control of a space booster rocket and a satellite, an automatic aircraft landing system, aircraft stabilization in the turbulent air-flow, stabilization of a cabin in a ship etc. RIP is a test bed for the study of various controllers like PID controller, LQR controller, and fuzzy controller. A normal pendulum is stable when hanging downwards, an inverted pendulum is inherently unstable, and must be actively balanced in order to remain upright, this can be done either by applying a torque at the pivot point, by moving the pivot point horizontally as part of a feedback system.

In this paper controllers are developed that keep the pendulum upright without any oscillations. The model is simulated using the MATLAB application. The paper is organized as follows. Section 2 deals with the modeling of the system, Section 3 discusses the control techniques PID, LQR, Fuzzy Logic and $\mathrm{H}$ infinity controllers, Section 4 gives the test bed results, Section 5 discusses the conclusion drawn from the analysis of these controllers in simulink and on test bed.

\section{Modelling of Rotary Inverted Pendulum}

The system, as shown in Fig. 1, consists of a vertical pendulum, a horizontal arm, a gear chain, and a servomotor which drives the pendulum through the gear transmission system. The rotating arm is mounted on the output gear of the gear chain. An encoder is attached to the arm shaft to measure the rotating angle of the arm. At the end of the rotating arm there is a hinge instrumented with an encoder. The pendulum is attached to the hinge. 


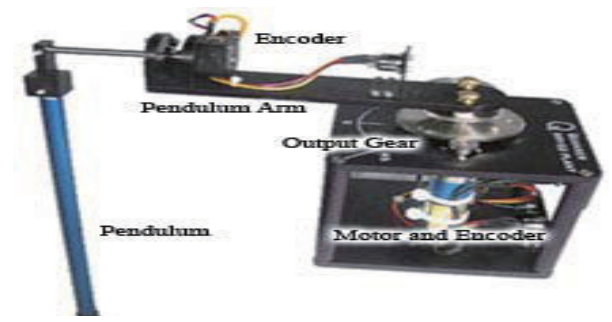

Fig.1. Rotary Inverted Pendulum system

The inverted pendulum is shown in Fig. 2, with its physical parameters $\alpha$ and $\theta$ are employed as the generalized coordinates to describe the inverted pendulum system. The pendulum is displaced with a given $\alpha$ while the arm rotates with an angle of $\theta$.

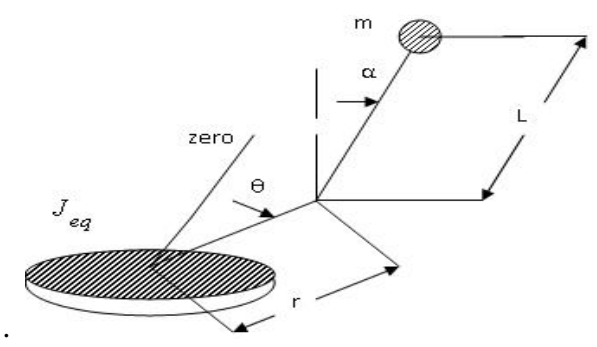

Fig.2. Figure showing physical parameters to be measured

Using the Lagrangian method [1], the equation of Rotary Inverted Pendulum is as follows:

$$
\begin{gathered}
\left(J+m r^{2}\right) \ddot{\theta}+\begin{array}{c}
m L r \sin (\alpha) \dot{\alpha}^{2}-m L r \cos (\alpha) \ddot{\alpha} \\
=T-B \dot{\theta}
\end{array} \\
\frac{4}{3} m L^{2} \ddot{\alpha}-m L r \cos (\alpha) \ddot{\theta}-m g L \sin \alpha=0
\end{gathered}
$$

Where Torque $\mathrm{T}$ is given as, $\quad T=\eta_{m} \eta_{g} K_{t} K_{g} \frac{V-K_{g} K_{m} \dot{\theta}}{R_{m}}$

Table I

PHYSICAL PARAMETERS OF THE SYSTEM

\begin{tabular}{|c|c|c|}
\hline Parameter & Description & Value(SI) \\
\hline $\mathrm{J}$ & $\begin{array}{c}\text { Moment of inertia at the } \\
\text { load }\end{array}$ & 0.0033 \\
\hline $\mathrm{m}$ & Mass of pendulum arm & 0.1250 \\
\hline $\mathrm{r}$ & Rotating arm length & 0.2150 \\
\hline
\end{tabular}


International Journal of Chaos, Control, Modelling and Simulation (IJCCMS) Vol.3, No.1/2, June 2014

\begin{tabular}{|c|c|c|}
\hline $\mathrm{L}$ & $\begin{array}{c}\text { Length to pendulum's } \\
\text { center of mass }\end{array}$ & 0.1675 \\
\hline $\mathrm{g}$ & Gravitational constant & 9.81 \\
\hline $\mathrm{B}$ & $\begin{array}{c}\text { Viscous damping } \\
\text { coefficient }\end{array}$ & 0.0040 \\
\hline$K_{t}$ & Motor torque constant & 0.0077 \\
\hline$K_{q}$ & SRV02 system gear ratio & 70 \\
\hline$K_{m}$ & Back-EMF constant & 0.0077 \\
\hline$R_{m}$ & Armature resistance & 2.6 \\
\hline$\eta_{m}$ & Motor efficiency & 0.69 \\
\hline$\eta_{q}$ & Gear efficiency & 0.90 \\
\hline
\end{tabular}

Solving the equations (1), (2) and (3) and values from the Table I, state space model is formed which is written as,

$$
\left[\begin{array}{c}
\dot{\theta} \\
\dot{\alpha} \\
\ddot{\theta} \\
\ddot{\alpha}
\end{array}\right]=\left[\begin{array}{cccc}
0 & 0 & 1 & 0 \\
0 & 0 & 0 & 1 \\
0 & 39.32 & -14.52 & 0 \\
0 & 81.78 & -13.98 & 0
\end{array}\right]\left[\begin{array}{c}
\theta \\
\alpha \\
\dot{\theta} \\
\dot{\alpha}
\end{array}\right]+\left[\begin{array}{c}
0 \\
0 \\
25.54 \\
24.59
\end{array}\right] V
$$

The state space parameters [2] are written as,

$$
\begin{gathered}
A=\left[\begin{array}{cccc}
0 & 0 & 1 & 0 \\
0 & 0 & 0 & 1 \\
0 & 39.32 & -14.52 & 0 \\
0 & 81.78 & -13.98 & 0
\end{array}\right] ; B=\left[\begin{array}{c}
0 \\
0 \\
25.54 \\
24.59
\end{array}\right] \\
C=\left[\begin{array}{cccc}
1 & 0 & 0 & 0 \\
0 & 1 & 0 & 0
\end{array}\right] ; \quad \mathrm{D}=0 ;
\end{gathered}
$$

\section{Controller Design}

\subsection{PID Controller}

Proportional, integral derivative are the controllers whose output, a control variable (CV), is generally based on the error (e) between some user-defined set point (SP) and some measured process variable $(\mathrm{PV})$. 
International Journal of Chaos, Control, Modelling and Simulation (IJCCMS) Vol.3, No.1/2, June 2014

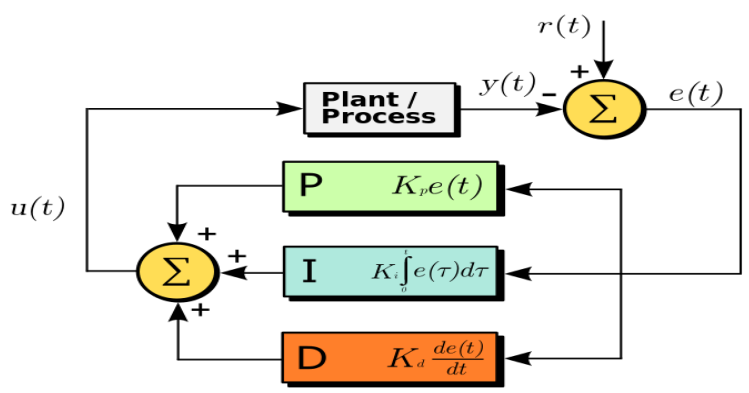

Fig.3. Schematic diagram for the closed loop system with force as a disturbance

The transfer function of PID is written as [3]

$$
K(s)=K_{p}+\frac{K_{i}}{s}+K_{d} s
$$

Manual tuning method is used to determine the gains [4].

$\mathrm{K}_{\mathrm{i}}$ and $\mathrm{K}_{\mathrm{d}}$ are set to zero. Then, $\mathrm{K}_{\mathrm{p}}$ is increased until the output of the loop oscillates, after obtaining optimum $\mathrm{K}_{\mathrm{p}}$ value, it is set to approximately half of that value for a "quarter amplitude decay" type response. Then, $\mathrm{K}_{\mathrm{i}}$ is increased until any offset is corrected in sufficient time for the process. However, too much $\mathrm{K}_{\mathrm{i}}$ will cause instability. Finally, $\mathrm{K}_{\mathrm{d}}$ is increased, until the loop is acceptably quick to reach its reference after a load disturbance [5].

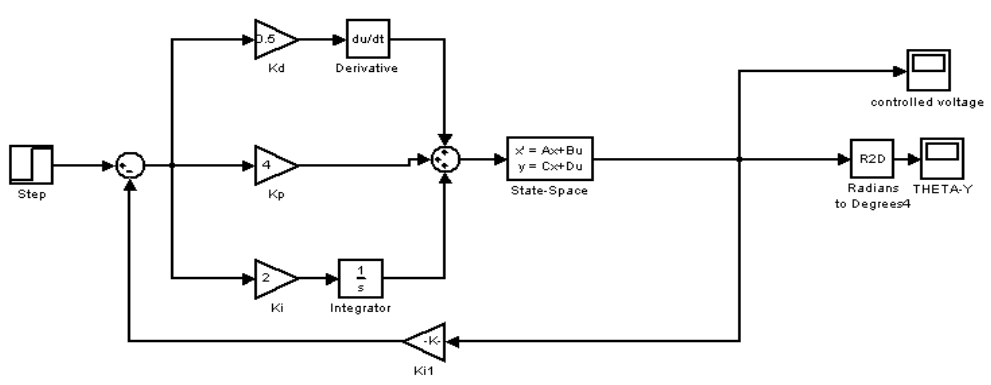

Fig.4. Simulink diagram of system using PID controller

Tuning the gain values $\mathrm{K}_{\mathrm{p}}, \mathrm{K}_{\mathrm{i}}, \mathrm{K}_{\mathrm{d}}$ with $4,2,0.5$ respectively along with a negative feedback as shown in the simulink model of Fig.4, the position of pendulum gets stabilized as shown in Fig 5. 
International Journal of Chaos, Control, Modelling and Simulation (IJCCMS) Vol.3, No.1/2, June 2014

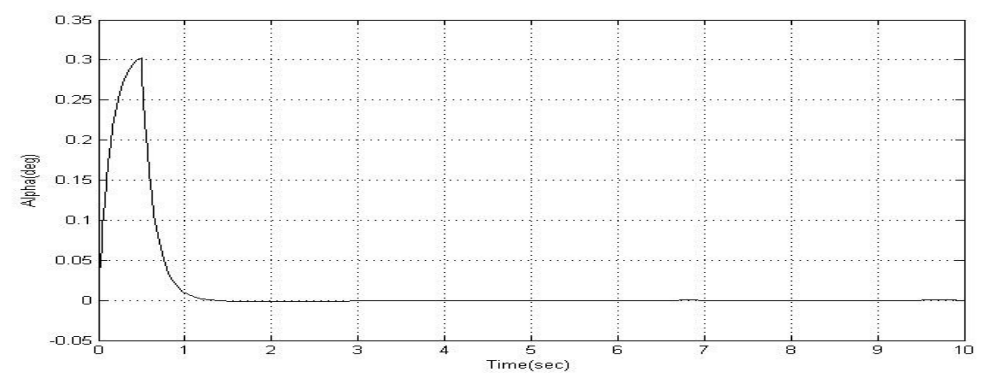

Fig.5 Variation of pendulum angle alpha (deg) with time (sec)

From Fig 5, it is observed that using PID control pendulum angle becomes zero within 1 second.

\subsection{LQR Controller}

$\mathrm{LQR}$ is a method in modern control theory that uses state-space approach to analyze a system like inverted pendulum. The theory of optimal control is concerned with operating a dynamic system at minimum cost. The case where system dynamics are described by a set of linear differential equations and the cost is described by quadratic functions which are called LQ problem [6]. The goal of such problem is to find an optimal control that minimizes a quadratic cost functional associated with a linear system.

A system is expressed in state variable form as,

$$
\dot{x}=A x+B u
$$

The initial condition is $x(0)$. Assuming here all the states measurable and seek to find a statevariable feedback (SVFB) control

$$
u=-K x+v
$$

To design a SVFB that is optimal, an Index called performance index (PI) is used and is given by,

$$
J=\frac{1}{2} \int_{0}^{\infty}\left(x^{T} Q x+u^{T} R u\right) d t
$$

Substituting the SVFB control equation in equation (1) yields

$$
J=\frac{1}{2} \int_{0}^{\infty} x^{T}\left(Q+K^{T} R K\right) x d t
$$

The objective in optimal design is to select the SVFB K that minimizes the performance index J. Solving equations(3) to (6), equation (7) is obtained,

$$
A^{T} P+P A+Q+K^{T} R K-K^{T} B^{T} P-P B K=0
$$

taking, $K=R^{-1} B^{T} P$

it gives,

$$
A^{T} P+P A+Q-P B R^{-1} B^{T} P=0
$$

It is a matrix quadratic equation that is solved to get the value of auxiliary matrix P. After getting the value of matrix $\mathrm{P}$, SVFB gain $\mathrm{K}$ is determined. 
Gain value is found as,

$$
\mathrm{K}=\left[\begin{array}{ll}
-1.13 & 14.5 \\
-1.44 & 2.46
\end{array}\right]
$$

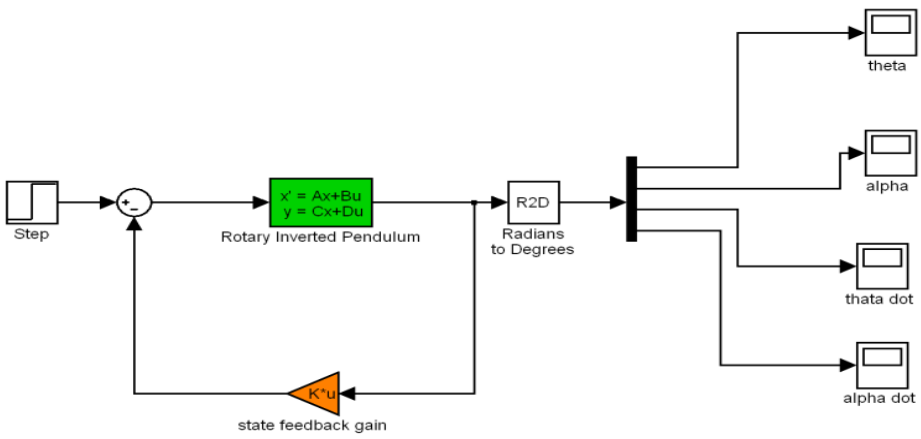

Fig.6 Simulink diagram of system using LQR control

By substituting the SVFB gain into the system and implemented in Simulink model of Fig.6, system gets stabilized. Fig 7 is the response of the pendulum position of the system.

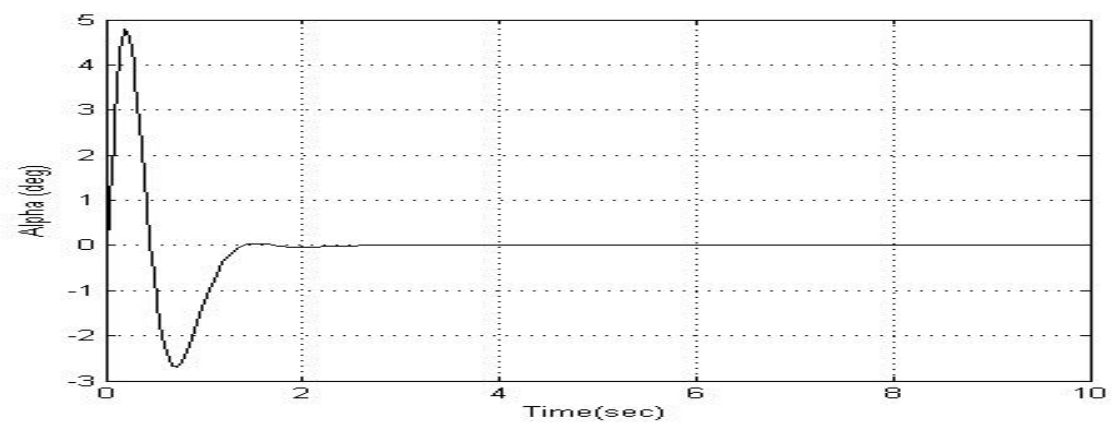

Fig. 7 Variation of pendulum position $\alpha$ (in deg) w.r.t time (in sec)

From Fig 7, it is observed that using LQR control, pendulum angle becomes zero within 1.5 seconds. Rotary Inverted Pendulum is stabilized at 34 degrees, and arm velocity becomes zero within 2 seconds.

Hence, Rotary Inverted Pendulum is stable within 1.5 seconds.

\subsection{Fuzzy Logic Controller (FLC)}

FLC provides a simple way to arrive at a definite conclusion based upon vague, ambiguous, imprecise, noisy, or missing input information [7]. FLC's approach to control problems mimics how a person makes decisions. Fuzzy control describes the algorithm for process control as a fuzzy relation between information about the condition of the process to be controlled, $\mathrm{x}$ and $\mathrm{y}$ and the input for the process. The control algorithm is given in the IF - THEN expression such as

if $\mathrm{x}$ is small and $\mathrm{y}$ is big then $\mathrm{z}$ is medium.

if $\mathrm{x}$ is big and $\mathrm{y}$ is medium, then $\mathrm{z}$ is big. 
The input and output variables as shown in FIS editor in Fig.8 are quantized into several modules or fuzzy subsets and the appropriate labels are assigned in this controller [8].

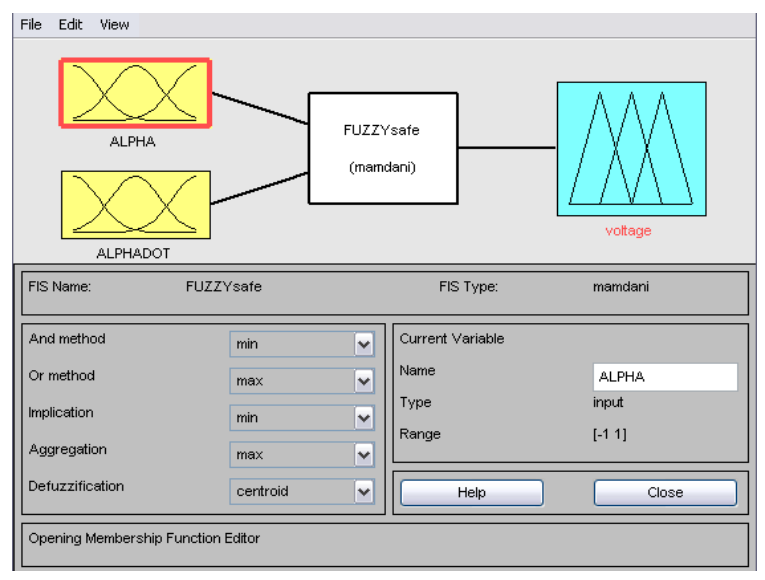

Fig. 8 FIS editor with two input and one output

There is FLC to control pendulum angle. Five fuzzy subsets have been taken to quantize each fuzzy variable for FLC as shown in Table II.

Table II

STANDARD LABELS OF QUANTIZATION

\begin{tabular}{|c|l|}
\hline Linguistic Term & Label \\
\hline Negative big & NB \\
\hline Negative small & NS \\
\hline Zero & ZE \\
\hline Positive small & PS \\
\hline Positive big & PB \\
\hline
\end{tabular}

Depending upon the range of alpha and alpha_dot, controlled voltage is decided. If alpha is NB and alpha_dot is PB then according to the rule base shown in Table III, the voltage applied to the system is zero.

Table III

FUZZY RULE BASE 
International Journal of Chaos, Control, Modelling and Simulation (IJCCMS) Vol.3, No.1/2, June 2014

\begin{tabular}{|l|l|l|l|l|l|}
\hline \multicolumn{1}{r|}{${ }_{\alpha}$} & & & & & \\
\cline { 3 - 6 } & NB & NS & Z & PS & PB \\
\hline NS & PB & PB & PB & PS & Z \\
\hline Z & PB & PS & Z & NS & NB \\
\hline PS & PS & Z & NS & NB & NB \\
\hline PB & Z & NS & NB & NB & NB \\
\hline
\end{tabular}

Fig. 9 and Fig.10 shows the simulink model and simulation result of the system using fuzzy logic controller:

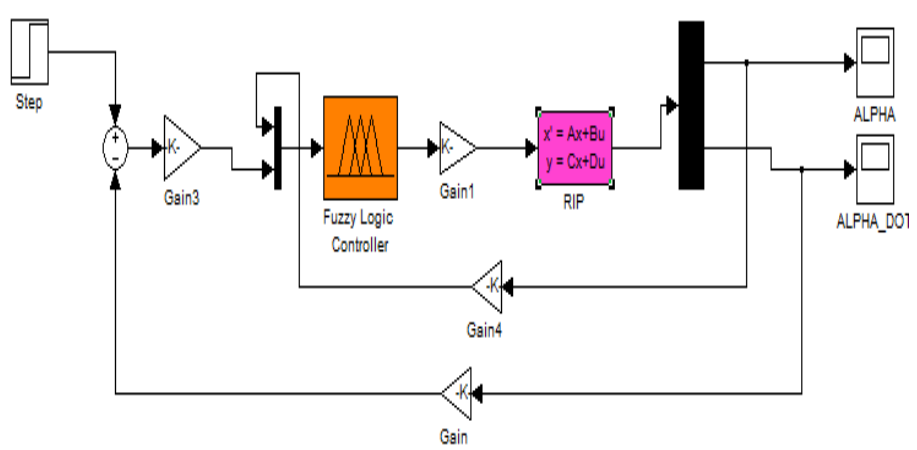

Fig. 9. Simulink diagram of system for fuzzy logic controller

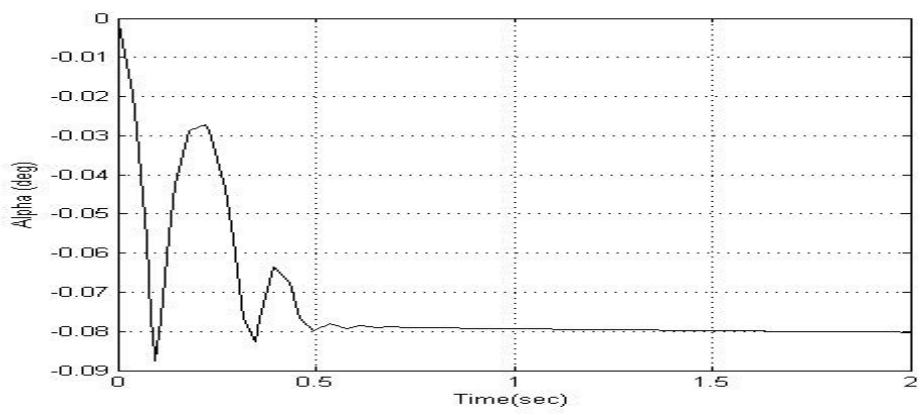

Fig. 10. Variation of pendulum angle with time (sec)

From results it is concluded that using fuzzy logic controller Rotary Inverted pendulum is stabilized within $0.5 \mathrm{sec}$.

\subsection{H infinity controller}

In order to achieve robust performance or stabilization, the H-Infinity control method is used. The $\mathrm{H} \infty$ name derives from the fact that mathematically the problem may be set in the space $H \infty$, 
International Journal of Chaos, Control, Modelling and Simulation (IJCCMS) Vol.3, No.1/2, June 2014

which consists of all bounded functions that are analytic in the right-half complex plane [9]. Hळ method is also used to minimize the closed loop impact of a perturbation depending on the problem formulation the impact will be measured in terms of either stabilization or performance.

This problem is defined by the configuration of Fig 11.

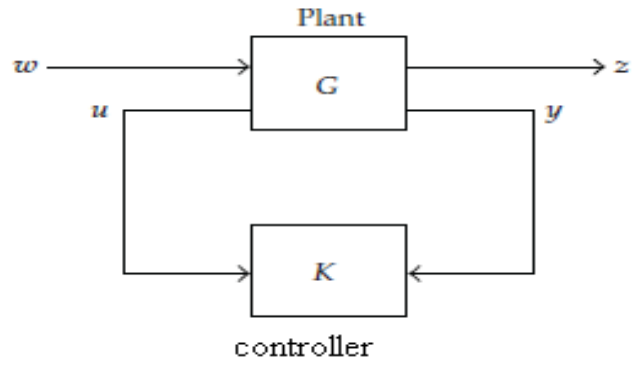

Fig.11 Generalized plant

The "plant" is a given system with two inputs and two outputs. It is often referred to as the generalized plant [9]. The signal $w$ is an external input and represents driving signals that generate disturbances, measurement noise, and reference inputs. The signal $u$ is the control input. The output $z$ has the meaning of control error and ideally should be zero. The output $y$, finally, is the observed output and is available for feedback.

The augmented plant is formed by accounting for the weighting functions $W_{1}, W_{2}$, and $W_{3}$ as shown in the Fig 12.

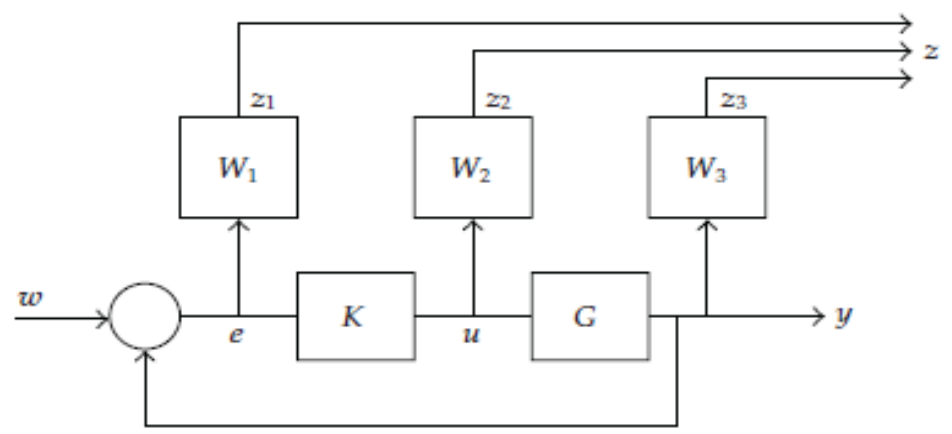

Fig.12. Plant with weighting functions for $\mathrm{H} \infty$ design

Choosing weights $\mathrm{W}_{1}, \mathrm{~W}_{2}$ and $\mathrm{W}_{3}$ as,

$$
\begin{gathered}
\mathrm{W}_{1}=0.99 *(\mathrm{~s}+50) /(\mathrm{s}+.001) ; \\
\mathrm{W}_{2}=1 ; \\
\mathrm{W}_{3}=10 *(\mathrm{~s}+50) /(\mathrm{s}+500) ;
\end{gathered}
$$

Using weights, controller in the form of state space form is obtained, 
International Journal of Chaos, Control, Modelling and Simulation (IJCCMS) Vol.3, No.1/2, June 2014

$$
A=\left[\begin{array}{ccccc}
-0.001 & 0 & 0 & 0 & 0 \\
8.356 e-025 & -500 & 82.33 & 0 & 0 \\
6.685 \mathrm{e}-024 & -3.829 \mathrm{e}-007 & -15.08 & 0 & 1 \\
-110.9 & 0.6872 & -425.9 & 48.48 & -84.08 \\
-106.7 & 0.6616 & -454 & 46.67 & -80.95
\end{array}\right]
$$

$$
\mathrm{B}=\left[\begin{array}{c}
11.11 \\
-3.961 \\
-23.69 \\
-42.23 \\
-178.7
\end{array}\right]
$$$$
\mathrm{C}=\left[\begin{array}{lllll}
-2.763 & 0.01 & -10.92 & 1.57 & -2
\end{array}\right]
$$

$$
\mathrm{D}=[0]
$$

The new state space model which is obtained is implemented in simulink diagram (Fig.13) as a feedback and pendulum angle alpha is observed in Fig.14.

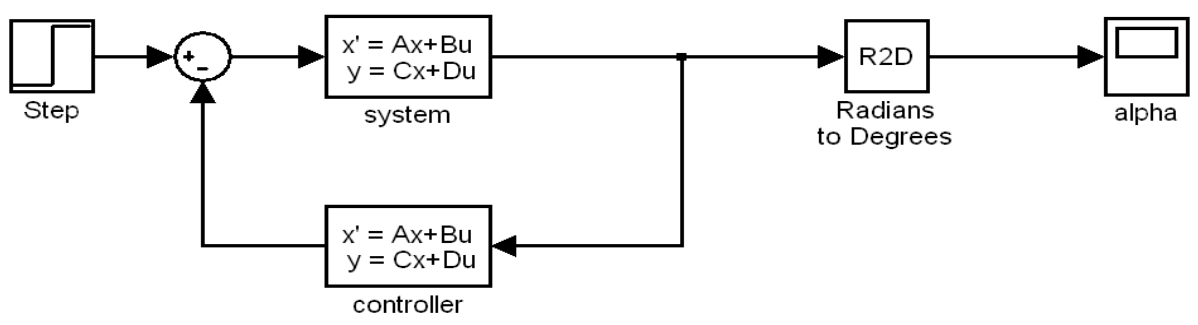

Fig.13. Simulink diagram of system using $\mathrm{H}$ infinity control

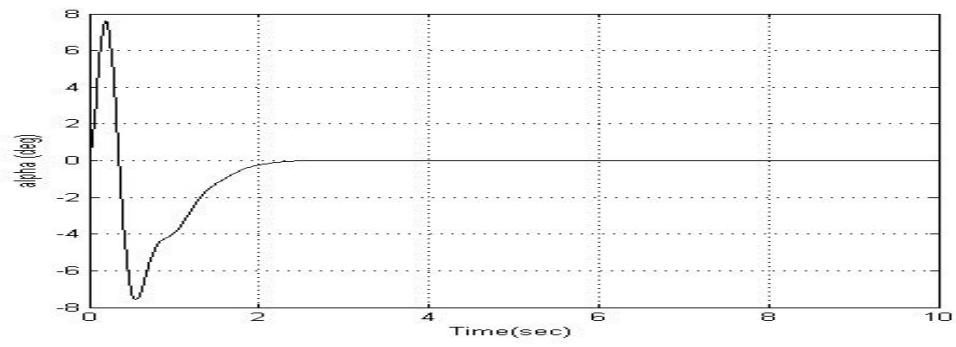

Fig.14 Variation of pendulum angle with time (sec) 
International Journal of Chaos, Control, Modelling and Simulation (IJCCMS) Vol.3, No.1/2, June 2014

\section{Test Bed Results}

\subsection{PID Controller}

Real time results of alpha i.e. pendulum angle using PID control is shown in Fig.15. Here, controller is activated as soon as pendulum reaches to the reference position and pendulum is stabilized.

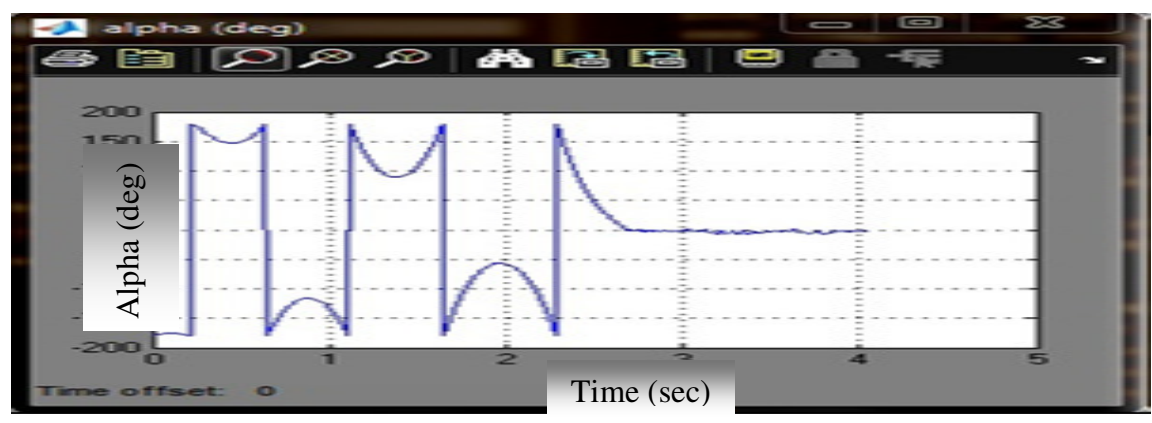

Fig.15 Real time result of system using PID control

\subsection{LQR Controller}

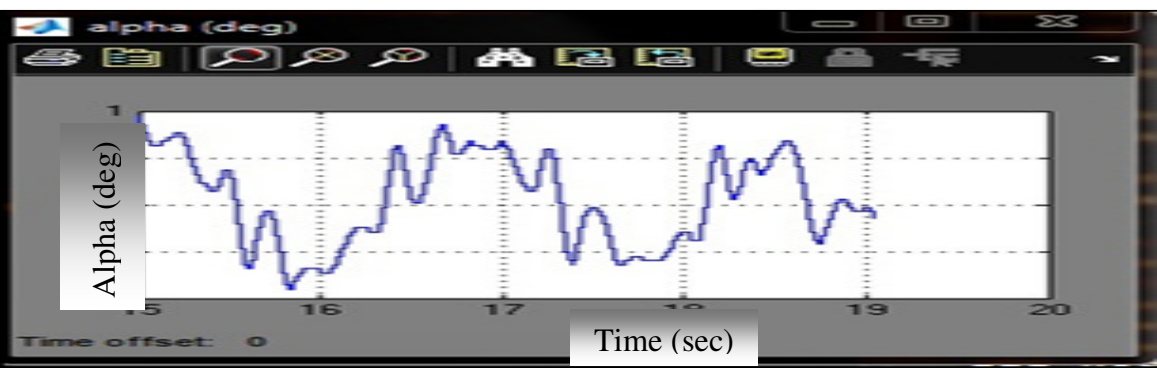

Fig.16 Real time result of system using LQR control

Fig.16 shows the real time results of alpha i.e. pendulum angle and controlled voltage using Linear Quadratic Control. Here, pendulum is oscillating between 1 and -3 degrees which is approximately negligible. 


\subsection{Fuzzy Logic Controller}

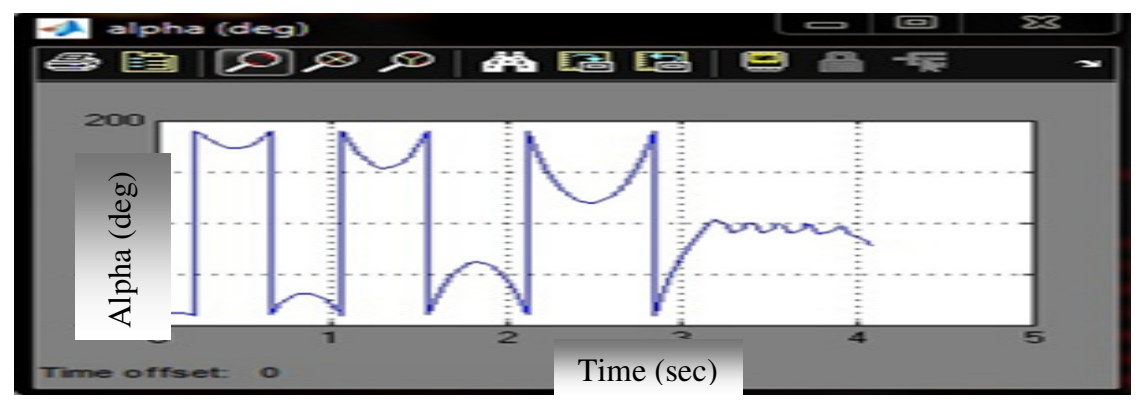

Fig.17 Real time result of system using FUZZY LOGIC control

Fig. 17 shows the real time results of alpha i.e. pendulum angle and controlled voltage using fuzzy logic controller. Here, controller is activated as soon as pendulum reaches to the reference position and pendulum is slightly oscillating.

\section{Conclusion}

\subsection{COMPARISON OF SIMULATION RESULTS}

In this section comparison of all the four controllers based on Simulation Results are discussed. Parameters compared are percentage peak overshoot and rise time as shown in Table IV.

Table IV

Comparison of controllers based on simulation results

\begin{tabular}{|c|l|l|}
\hline Controller & $\begin{array}{l}\text { Peak overshoot } \\
(\% \mathbf{M p})\end{array}$ & Rise time $\left(\mathbf{t}_{\mathbf{r}}\right)$ \\
\hline PID & 0.3 & 0.1 \\
\hline LQR & 4.8 & 0.1 \\
\hline Fuzzy Logic & 0.09 & 0.05 \\
\hline H $\infty$ & \multicolumn{1}{|c|}{7.8} & 0.25 \\
\hline
\end{tabular}

Comparing simulation results of all the four controllers, from the Table IV, it is concluded that, percentage peak overshoot is less in case of Fuzzy Logic controller as compared to other three controllers. Rise time is also less for this controller.

\subsection{COMPARISON OF TEST BED RESULTS}


International Journal of Chaos, Control, Modelling and Simulation (IJCCMS) Vol.3, No.1/2, June 2014

In this section comparison of all the four controllers based on Test bed Results are discussed. Parameters compared are percentage peak overshoot and rise time as shown in Table V.

Table V : Comparison of controllers based on Test Bed results

\begin{tabular}{|l|l|l|}
\hline Controller & $\begin{array}{l}\text { Peak overshoot } \\
(\boldsymbol{\%} \mathbf{M p})\end{array}$ & Rise time $\left(\mathbf{t}_{\mathbf{r}}\right)$ \\
\hline PID & 2 & 0.3 \\
\hline LQR & 2.5 & 0.5 \\
\hline Fuzzy Logic & 10 & 0.1 \\
\hline H $\infty$ & -- & -- \\
\hline
\end{tabular}

Comparing test bed results of PID, LQR and FUZZY LOGIC, from the Table V it is concluded that, percentage peak overshoot as well as rise time of response is less for LQR controller as compared to PID and Fuzzy Logic controller

\section{REFERENCES}

[1] Quanser Inc.SRV02 Exp7 Inverted Pendulum.pdf.2003

[2] Quanser Inc.SRV02 Exp1 position control.pdf.2003

[3] T.Sugie and K. Fujimoto, "Controller design for an inverted pendulum based on approximate linearization,” Int. J. of Robust and Nonlinear control, vol. 8, no 7, pp. 585-597, 1998.

[4] Katebi M R and M.H. Moradi (2001):"Predictive PID Controllers". IEE Proc. Control Theory Application, Vol. 148, No. 6; November 2001, pp. 478-487.

[5] K. Ang, G. Chong, and Y. Li, "PID control system analysis, design and technology," IEEE Trans.Control System Technology, vol. 13, pp. 559-576, July 2005.

[6] Md. Akhtaruzzaman and A. A. Shafie, "Modeling and Control of a Rotary Inverted Pendulum Using Various Methods, Comparative Assessment and Result Analysis", Proceedings of the 2010 IEEE, International Conference on Mechatronics and Automation, August 4-7, 2010, Xi'an, China

[7] Chen Wei Ji, Fang Lei, Lei Kam Kin, I997 IEEE International Conference on Intelligent Processing System October 28 - 31."Fuzzy Logic Controller for an Inverted Pendulum System"

[8] Muskinja, N. and B. Tovornik, 2006. "Swinging up and stabilization of a real Inverted pendulum". IEEE Trans. Ind. Elect., 53. DOI: 10.1109/TIE.2006.870667

[9] Ximena CeliaM’endez Cubillos and Luiz Carlos Gadelha de Souza, 2009."Using of H-Infinity Control Method in Attitude Control System of Rigid-Flexible Satellite", Hindawi Publishing Corporation Mathematical Problems in Engineering Volume 2009, Article ID 173145, 9 pages doi:10.1155/2009/173145 